Research Article

\title{
Distribution and Ecologica Risk of Sediment Heavy Metals in the Water-Level-Fluctuation Zone of the Shawan River Section of Yelang Lake
}

\author{
Xiaojuan Zhang $\mathbb{D}^{1,2,3}$ and Yutao Zhang $\mathbb{D}^{1,2}$ \\ ${ }^{1}$ College Rural Revitalization Research Center of Guizhou, Anshun 561000, Guizhou, China \\ ${ }^{2}$ Engineering Technology Center of Control and Remediation of Soil Contamination of Provincial Science \& Technology Bureau, \\ Anshun 561000, Guizhou, China \\ ${ }^{3}$ School of Chemistry and Chemical Engineering, Anshun University, Anshun 561000, Guizhou, China
}

Correspondence should be addressed to Xiaojuan Zhang; zxj9583@126.com and Yutao Zhang; zyt0516@126.com

Received 11 June 2021; Accepted 14 August 2021; Published 23 August 2021

Academic Editor: Yaqiong Su

Copyright (c) 2021 Xiaojuan Zhang and Yutao Zhang. This is an open access article distributed under the Creative Commons Attribution License, which permits unrestricted use, distribution, and reproduction in any medium, provided the original work is properly cited.

\begin{abstract}
With the aim of revealing the potential ecological risk and distribution characteristics of heavy metals on the surface sediment at the Shawan River section of Yelang Lake, the following three analyses were first performed: (1) analysis of grain-size composition on sediment samples collected at seven different sites in the water-level-fluctuation zone (WLFZ); (2) analysis of bulk sediment content of six heavy metals, namely, $\mathrm{Cd}, \mathrm{Cr}, \mathrm{Pb}, \mathrm{Mn}, \mathrm{Zn}$, and $\mathrm{Cu}$; and (3) the correlation analysis of grain-size composition and heavy metal content in the sediment. Afterwards, the approach of Hakanson potential ecological risk index was employed to analyze the risk of heavy metal pollution in sediments of seven WLFZ plots. The outcomes indicate that (1) the mean sediment grain size at each sampling site was generally $>0.063 \mathrm{~mm}$, with gravel grains $(>1 \mathrm{~mm})$ and sand grains $(0.22-1 \mathrm{~mm})$ accounting for the largest proportions; (2) the site-averaged mean sediment content of each of the six heavy metals was significantly higher than their respective geochemical background contents in the sediment of Guizhou Province, and the grain-size dependence of the bulk sediment content of heavy metals was not significant; (3) the distribution of Cr was relatively independent of other metals, which was in contrast to notable positive correlations observed between other metals; and (4) in accordance with the approach of Hakanson potential ecological risk index, for these heavy metals, their potential ecological risk reduced by the order of $\mathrm{Zn}<\mathrm{Cr}<\mathrm{Cu}<\mathrm{Pb}<\mathrm{Cd}$, with $\mathrm{Cd}$ having a mean potential risk index $\left(E_{i}\right)$ of 566.13 , suggestive of a very high level of potential ecological risk, $\mathrm{Zn}, \mathrm{Cr}$, and $\mathrm{Cu}$ having a mild potential ecological risk, and $\mathrm{Pb}$ having moderate potential ecological risk. Cd largely contributes to the comprehensive ecological risk index RI is the largest, thereby having important environmental implications.
\end{abstract}

\section{Introduction}

Water-level-fluctuation zone (WLFZ) is a transition zone and a special ecological area between waters and terrestrial ecosystems, where there is active transport and transformation of soil material and energy, characterized by frequent human activities and ecological vulnerability [1]. Heavy metals and other pollutants not only in WLFZ soil enter the water column through dissolution, exchange, and diffusion to cause changes in water quality but also in the water column migrate to the WLFZ through adsorption and precipitation to cause changes in the soil environment [2-5]. Heavy metals are enriched on the surface of sediment grains, and the transformation and migration of heavy metals utilizing the grains as the carriers are influenced via various external environmental conditions in addition to anthropogenic activities [6]. Sediment particle size is one of the most significant factors influencing the adsorption capacity of heavy metals in soil [7]. The size of sediment grain directly influences the hydrodynamic properties, specific surface area, adsorption or desorption capacity of sediment, and consequently the heavy metal content in sediment [8]. 
Therefore, insights into the grain-size distribution characteristics of WLFZ soil, the relationship between heavy metal distribution and soil grain-size distribution, and the pollution level of the heavy metal, together with identification of the pollution sources, are of great importance for the soil and water environment protection in WLFZ.

Yelang Lake is the second-largest reservoir in Guizhou Province, located in Puding County, China. Yelang Lake not only serves as a water source for agricultural and industrial activities but also has been used for water storage and regulation, flood control, tourism, and climate regulation, playing a vital role in the socioeconomic development of Anshun City, Guizhou. Mining activities started around Yelang Lake in 2007, and although they have been prohibited by the government since 2014 , heavy metal pollution is still present on the surface sediment and shoreline soil of Yelang Lake [9].

Extensive studies on the grain size of aqueous sediment have been reported [10-12], mainly focusing on the size composition and distribution of sediment gains, as well as the effects of the grain size of aqueous sediment on the bioavailability, adsorption, and distribution of heavy metals. However, systematic studies on the relationship between the sediment grain-size composition and heavy metals bulk content (as a mass fraction) of WLFZ sediment are rare. In this study, we determined the volume contents of six typical heavy metals and the sediment grain-size composition, analyzed the correlation between the total sediment content of each heavy metal and the grain-size fractions of sediment, and evaluated the influences of human activities against the spatial distribution of sediment grain-size fractions and heavy metals, thereby revealing the ecological risk of heavy metals in sediment in WLFZ of Shawan Reach of Yelang Lake. The findings may provide scientific and technical support for the comprehensive management and ecological restoration of Yelang Lake.

\section{Materials and Methods}

2.1. Research Area. Yelang Lake $\left(105^{\circ} 48^{\prime} \mathrm{E}, 26^{\circ} 23^{\prime} \mathrm{N}\right)$ locates in Puding County, about $35 \mathrm{~km}$ north of Anshun City in southwest China, and it is the second-largest man-made reservoir in Guizhou Province. It is the drinking water source of approximately 2.5 million residents in Anshun City, with an area of 19.5 square kilometers, a storage capacity of 420 million $\mathrm{m}^{3}$, and a total length of $42 \mathrm{~km}$. In October 2002, the Standing Committee of Guizhou Provincial People's Congress promulgated the Regulations on Water Resources and Environmental Protection of Yelang Lake in Guizhou Province. As approved by the Guizhou provincial government in March 2004, the primary protection zone of the drinking water source of Yelang Lake is $5.6 \mathrm{~km}^{2}$, and the secondary protection zone is $22.5 \mathrm{~km}^{2}$. The delineation plan of the quasiprotection zone of Yelang Lake drinking water source was approved by the Anshun municipal government on March 31, 2006, covering an area of $247.5 \mathrm{~km}^{2}$. The Shawan River section locates in the secondary protection zone of Yelang Lake and is under a subtropical humid monsoon climate with $1,378 \mathrm{~mm}$ of annual average precipitation and $17.9^{\circ} \mathrm{C}$ of annual mean temperature. The WLFZ of the Shawan River section of Yelang Lake is sparse in vegetation and mostly has karst topography, with a slope of approximately $6^{\circ}$, thin top-soil layers, and little organic matter content.

2.2. Soil Sample Collection. To reduce the confounding effects of soil type and topography on the analysis results of soil heavy metals, seven WLFZ sites $(A-G)$ with similar slopes, slope aspects, and land-use histories and under nearly natural conditions were selected for sediment sampling in December 2017 when Yelang Lake was in the dry season and there was no rainstorm 20 days in prior to sampling, considering the local inundation times. Site A was at the boundary between the lake water surface and the WLFZ, site $B$ was in the WLFZ $10 \mathrm{~m}$ far from the lake water surface, site $\mathrm{C}$ was $20 \mathrm{~m}$ away, site $\mathrm{D}$ was $30 \mathrm{~m}$ away, site $\mathrm{E}$ was at a distance of $40 \mathrm{~m}$, site $\mathrm{F}$ was $50 \mathrm{~m}$ away, and site $\mathrm{G}$ was $60 \mathrm{~m}$ away, with an elevation difference of approximately $1 \mathrm{~m}$ between two adjacent sampling sites. No land-use activities had occurred in these sites. Surface sediment samples $(0-10 \mathrm{~cm})$ were collected in duplicate at each sampling site using a grab sampler, placed in self-sealing bags, brought back to the laboratory, and stored at $0-4^{\circ} \mathrm{C}$ before subsequent analysis.

2.3. Sample Processing and Analysis. For each sampling site, the soil samples collected at the same depth were mixed thoroughly, the impurities were removed, and the samples were air-dried, vacuum freeze-dried, ground, and sieved into fractions of grain size $>1 \mathrm{~mm}, 0.22-1 \mathrm{~mm}, 0.125-0.22 \mathrm{~mm}$, $0.063-0.125 \mathrm{~mm}$, and $<0.063 \mathrm{~mm}$.

The sediment samples of WLFZ were dissolved into PTFE tubes with nitric acid and hydrofluoric acid, sealed in steel cylinders, and kept in a muffle furnace for one day at $180^{\circ} \mathrm{C}$ temperature. After the digestion solution was cooled, the mixture was boiled on a hot plate until it was dry. The resulting residue was mixed with diluted nitric acid and heated in an oil bath at $140^{\circ} \mathrm{C}$ for $4 \mathrm{~h}$ to ensure full dissolution, followed by diluting the resulting solution to $100 \mathrm{~mL}$. ICP-MS (7700e, Agilent Technologies, MA, USA) was employed to determine the concentration of heavy metals in the diluted solution.

2.4. Quality Control for Sample Analysis. The concentrations of heavy metals were detected via standard materials, calibrated by every twenty samples. Data precision and accuracy were determined with blank sample experiments, recovery experiments, and parallel experiments.

2.5. Potential Ecological Risk Index Method. The approach of potential ecological risk index considers the heavy metals content in sediments as well as their ecological and environmental effects and toxicity levels and has been widely adopted for the assessment of the sediment potential ecological risk, with the grading criteria shown in Table 1 . In this method, the comprehensive potential ecological risk index 
TABLE 1: The classification of multiple heavy metal comprehensive potential ecological risk index (RI) and single heavy metal potential ecological risk index $\left(E_{r}^{i}\right)$.

\begin{tabular}{|c|c|c|c|c|c|}
\hline Degree of pollution & Mild & Moderate & Strong & Very strong & Extremely strong \\
\hline Potential ecological risk index of single heavy metals $\left(E_{r}^{i}\right)$ & $<40$ & $40-80$ & $80-160$ & $160-320$ & $\geq 320$ \\
\hline Integrated potential ecological risk index of multiple heavy metals (RI) & $<150$ & $150-300$ & $300-600$ & $\geq 600$ & - \\
\hline
\end{tabular}

(RI) of various heavy metals and the heavy metal potential ecological risk index $\left(E_{r}^{i}\right)$ can be expressed as follows:

$$
\begin{aligned}
& E_{r}^{i}=T_{r}^{i} \cdot c_{f}^{i}, \\
& \mathrm{RI}=\sum_{i=1}^{n} E_{r}^{i}=\sum_{i=1}^{n} T_{r}^{i} \cdot c_{f}^{i}=\sum_{i=1}^{n} T_{r}^{i} \cdot \frac{c_{s}^{i}}{c_{n}^{i}},
\end{aligned}
$$

where $c_{f}^{i}$ represents the enrichment factor of heavy metal $i$; $c_{s}^{i}$ represents the content of heavy metal $i$ determined; $c_{n}^{i}$ refers to the reference value needed for the calculation, which is the maximum background content of heavy metal $i$ in the modern preindustrial normal sediment particles; and $T_{r}^{i}$ stands for the toxicity response factor of heavy metal $i$, which reflects the sensitivity of the environment to heavy metal pollution and the level of heavy metal $i$ toxicity. The toxicity response coefficients and reference values of heavy metals are revealed in Table 2, and the potential ecological risk level of Hakanson is exhibited in Table 1.

\section{Results and Analysis}

3.1. Grain-Size Composition of Surface Sediment at Different Sampling Sites (Corresponding to Different Inundation Times). The composition of grain size for WLFZ sediment in the Shawan River section of Yelang Lake is shown in Table 3. As illustrated in Table 3, the grain size of sediment from seven sampling sites was generally $>0.063 \mathrm{~mm}$, indicating that the surface sediment of the WLFZ of the Shawan River section of Yelang Lake was dominated by larger grains. The grain-size fractions of the WLFZ sediment included gravel $(>1 \mathrm{~mm})$, sand $(0.22-1 \mathrm{~mm})$, fine sand $(0.125-0.22 \mathrm{~mm})$, and very fine sand $(0.063-0.125 \mathrm{~mm})$, jointly accounting for more than $95 \%$ of the total grains. In particular, gravel and sand jointly accounted for the largest proportion (more than 75\%), followed by fine sand $(8.22-13.90 \%)$, very fine sand $(4.77-10.45 \%)$, and silt (3.22-4.12\%). The present results differed from the observation that the sediment grain size of the WLFZ of Three Gorges Reservoir is mainly in the range of $0.02-0.002 \mathrm{~mm}$. This discrepancy may be attributed to the fact that WLFZ sediments in different geographical areas experience the drainage-inundation process to varying degrees, and such drying-wetting cycles have a significant effect on sediment grain-size composition, which generally leads to sediment grain-size parameters specific to the local sedimentary conditions [13].

Although different grain-size fractions showed different content trends with sampling sites, one-way ANOVA revealed an extremely significant difference among all sampling sites with regard to the sediment content of gravel versus sand $(P<0.01)$ and significant differences among all sampling sites in the sediment content of silt, very fine sand,
TABLE 2: Toxic response factors of heavy metals.

\begin{tabular}{lccccc}
\hline Item & $\mathrm{Zn}$ & $\mathrm{Cu}$ & $\mathrm{Cd}$ & $\mathrm{Cr}$ & $\mathrm{Pb}$ \\
\hline Toxic response factor & 1 & 5 & 30 & 2 & 5 \\
\hline
\end{tabular}

and fine sand $(P<0.05)$, suggesting that inundation time had a significant effect on the spatial differentiation of sediment grain composition in the WLFZ.

\subsection{Distribution of the Sediment Content of Heavy Metals.} Figure 1 presents the sediment content of each of the six heavy metals in various sampling points (corresponding to different inundation times) in the WLFZ of the Shawan River section of Yelang Lake as well as the site-averaged mean sediment content. The site-averaged mean sediment content of each heavy metal was higher than the respective geochemical background content in the sediment of Guizhou Province. Specifically, the mean sediment content of $\mathrm{Pb}$ reached $290.20 \mu \mathrm{g} \cdot \mathrm{g}^{-1}$, a value 9.87 times more than the background content. This high content was mainly attributed to the inputs of $\mathrm{Pb}$ into the sediment from the leachate of the $\mathrm{Pb}-\mathrm{Zn}$ mine upstream of Yelang Lake. The results also showed serious $\mathrm{Cr}, \mathrm{Cu}, \mathrm{Zn}$, and $\mathrm{Mn}$ pollution with mean contents of $258.91,119.60,507.36$, and $1,372.45 \mu \mathrm{g} \cdot \mathrm{g}^{-1}$, respectively; these values were $3.26,4.05,5.64$, and 1.27 times more than the background content, respectively. In particular, Cd pollution was the most serious, with its mean content being 18.87 times more than the background content. These findings indicate that due to the relatively long history of upstream mining (dating to the last century) of Yelang Lake, the WLFZ sediment had already been contaminated in 2014 when upstream mining was prohibited. Accordingly, the pollution from the $\mathrm{Pb}-\mathrm{Zn}$ mine still poses a great threat to both the local biological system and the human food chain.

One-way ANOVA revealed significant differences among different WLFZ sampling sites in the sediment content of $\mathrm{Pb}, \mathrm{Zn}$, and $\mathrm{Cr}(P<0.05)$, but there are no remarkable differences in the sediment content of $\mathrm{Cu}, \mathrm{Cd}$, and $\mathrm{Mn}(P>0.05)$. This discrepancy may be attributed to the fact that the $\mathrm{Cu}, \mathrm{Cd}$, and $\mathrm{Mn}$ in WLFZ principally comes from the weathering of soil parent rock, which explained the absence of significant impacts of inundation time on $\mathrm{Mn}$, $\mathrm{Cd}$, and $\mathrm{Cu}$ sediment content. The maximum sediment content of $\mathrm{Cu}$ and $\mathrm{Cd}$ was found at sampling site $\mathrm{F}$, while the maximum $\mathrm{Pb}, \mathrm{Zn}, \mathrm{Mn}$, and $\mathrm{Cr}$ contents were found at sampling site B. Heavy metals are present in the soil in various forms, and each form has a different migration capacity. Heavy metals in exchangeable and carbonatebound states are weakly bound to the soil and are most easily released, with great mobility. Heavy metals in Fe-Mn oxides 
TABLE 3: Sediment grain-size composition at different sampling sites (corresponding to different inundation times).

\begin{tabular}{|c|c|c|c|c|c|}
\hline \multirow{2}{*}{ Sampling site } & \multicolumn{5}{|c|}{ Proportion (\%) } \\
\hline & Gravel, $>1 \mathrm{~mm}$ & Sand, $0.22-1 \mathrm{~mm}$ & Fine sand, $0.125-0.22 \mathrm{~mm}$ & Very fine sand grain, $0.063-0.125 \mathrm{~mm}$ & Silt, $<0.063 \mathrm{~mm}$ \\
\hline G & 33.21 & 41.26 & 11.00 & 10.45 & 4.09 \\
\hline $\mathrm{F}$ & 35.06 & 38.95 & 13.13 & 9.64 & 3.22 \\
\hline $\mathrm{E}$ & 39.30 & 39.98 & 12.20 & 8.65 & 4.12 \\
\hline $\mathrm{D}$ & 35.16 & 41.72 & 13.90 & 5.24 & 3.97 \\
\hline $\mathrm{C}$ & 49.70 & 31.31 & 10.74 & 4.62 & 3.63 \\
\hline B & 49.14 & 34.44 & 8.22 & 4.77 & 3.42 \\
\hline A & 45.54 & 31.56 & 11.36 & 8.06 & 3.46 \\
\hline
\end{tabular}
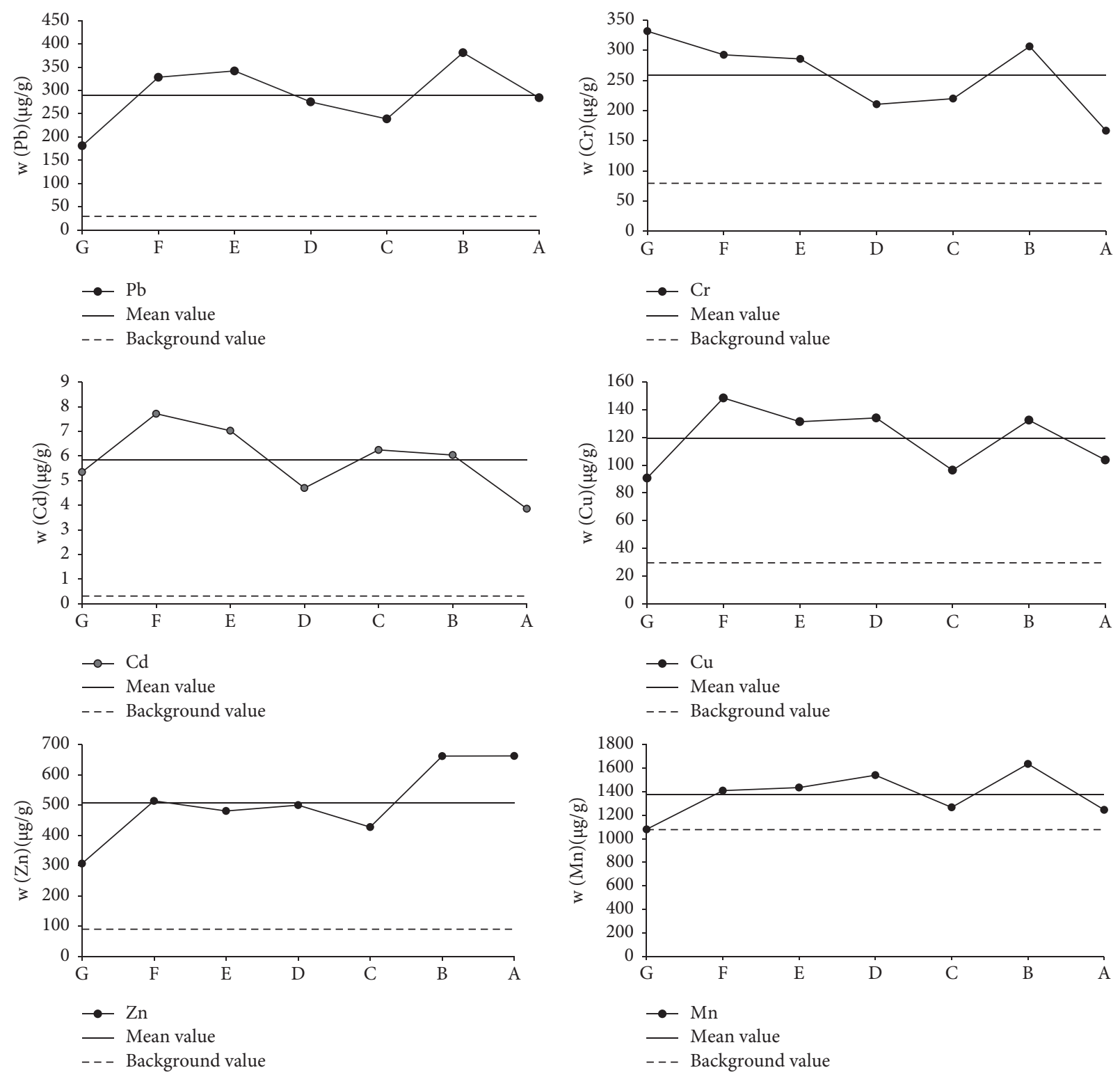

FIGURE 1: Average content $\left(\mu \mathrm{g} \cdot \mathrm{g}^{-1}\right)$ of the heavy metals in surface sediment from diverse sampling points.

easily dissolve and release under reducing conditions, while organic bound heavy metals are easily released through organic matter decomposition under oxidizing conditions [14]. Zhong et al. [15] reported that the soil content of each heavy metal form is jointly affected by soil $\mathrm{pH}$, organic matter, clay, silt, sand, cation exchange capacity (CEC), FeOx content, and MnOx content. Therefore, the observed differences among different sampling sites (corresponding to different inundation times) in the sediment content of heavy metals may be attributed to the different sediment properties 
TABLE 4: Spearman correlation coefficients of bulk sediment content of heavy metals (as a mass fraction) with sediment grain-size fractions.

\begin{tabular}{lcccccc}
\hline & $\mathrm{Pb}$ & $\mathrm{Cr}$ & $\mathrm{Cd}$ & $\mathrm{Cu}$ & $\mathrm{Zn}$ & $\mathrm{Mn}$ \\
\hline$>1 \mathrm{~mm}$ & 0.143 & -0.607 & 0.036 & -0.107 & 0.357 & 0.107 \\
$0.22-1 \mathrm{~mm}$ & -0.214 & 0.464 & -0.500 & 0.214 & -0.75 & 0.143 \\
$0.125-0.22 \mathrm{~mm}$ & -0.286 & -0.357 & 0.071 & 0.679 & -0.571 & 0.107 \\
$0.063-0.125 \mathrm{~mm}$ & -0.321 & 0.357 & -0.429 & -0.036 & $-0.821^{*}$ & -0.750 \\
$<0.063 \mathrm{~mm}$ & -0.357 & -0.286 & 0.000 & -0.286 & -0.464 & -0.071 \\
\hline
\end{tabular}

TABLE 5: The multiple heavy metals comprehensive potential ecological risk index (RI) and single heavy metal potential ecological risk index $\left(E_{r}^{i}\right)$ at distinct sampling sites.

\begin{tabular}{lccccccc}
\hline \multirow{2}{*}{ Sampling site } & \multicolumn{5}{c}{ Potential ecological risk index $\left(E_{r}^{i}\right)$} & Integrated potential ecological risk index $(\mathrm{RI})$ & Pollution level \\
& $\mathrm{Pb}$ & $\mathrm{Cr}$ & $\mathrm{Cd}$ & $\mathrm{Cu}$ & $\mathrm{Zn}$ & 575.73 & Strong \\
$\mathrm{G}$ & 30.83 & 8.35 & 517.74 & 15.40 & 3.41 & 841.27 & Very strong \\
$\mathrm{F}$ & 55.87 & 7.36 & 747.10 & 25.23 & 5.71 & 773.35 & Very strong \\
$\mathrm{E}$ & 58.18 & 7.19 & 680.32 & 22.32 & 5.34 & 535.33 & Strong \\
$\mathrm{D}$ & 46.85 & 5.30 & 454.84 & 22.78 & 5.56 & 672.13 & Very strong \\
$\mathrm{C}$ & 40.64 & 5.53 & 604.84 & 16.37 & 4.75 & 686.95 & Very strong \\
$\mathrm{B}$ & 64.85 & 7.71 & 584.52 & 22.51 & 7.36 & 451.55 & Strong \\
$\mathrm{A}$ & 48.83 & 4.19 & 373.55 & 17.62 & 7.36 & 648.04 & Very strong \\
Mean & 49.43 & 6.52 & 566.13 & 20.32 & 5.64 &
\end{tabular}

at these sites and thereby to different mobility of sediment heavy metals in various forms. More research is needed to gain deeper insights into the factors and mechanisms that influence the sediment content of heavy metals.

\subsection{Correlation Analysis of the Bulk Sediment Content of} Heavy Metals versus the Sediment Grain-Size Composition. Table 4 presents the correlation between the percent content of sediment grain-size fractions and the bulk sediment content of heavy metals. No significant correlation was observed, except for a significant negative correlation between the $0.063-0.125 \mathrm{~mm}$ fraction and $\mathrm{Zn}$, indicating that for the content of heavy metal in WLFZ sediment at the Shawan River section of Yelang Lake, the grain-size dependence was not evident. This suggests that $\mathrm{Cd}, \mathrm{Cr}, \mathrm{Pb}, \mathrm{Mn}$, $\mathrm{Zn}$, and $\mathrm{Cu}$ in WLFZ sediment of the research area may be derived from the same source(s).

3.4. Ecological Risk Assessment of Sediment Heavy Metals for Different Sampling Sites. The potential ecological risk index of heavy metals in the 7 sampling points is illustrated in Table 5. The outcomes indicate that the average potential ecological risk index of single heavy metals reduced with the order of $\mathrm{Zn}<\mathrm{Cr}<\mathrm{Cu}<\mathrm{Pb}<\mathrm{Cd}$, with large differences among different heavy metals. In particular, Cd possessed the highest potential risk among all heavy metals, with its $E_{r}^{i}$ reaching 747.10 at site $\mathrm{F}$. $\mathrm{Pb}$ had a slightly lower $E_{r}^{i}$, indicative of moderate ecological risk. In contrast, $\mathrm{Cu}, \mathrm{Cr}$, and $\mathrm{Zn}$ had low ecological risk, especially $\mathrm{Zn}$, for which the lowest and highest $E_{r}^{i}$ values among all sampling sites were 3.41 and 7.36, respectively.

The integrated ecological risk index (RI) suggested that the ecological risk of sediment had a periodic pattern. Specifically, sampling sites F, E, C, and B had very strong ecological risks, with mean RI values of 841.27, 773.35,
672.13, and 686.95, respectively, and sampling sites G, D, and A had strong ecological risks, with mean RI values of 575.73, 535.33, and 451.55, respectively. In addition, a comparison of single-metal potential risk indices revealed that $\mathrm{Cd}$ had the largest contribution among all heavy metals to the RI and thereby had important environmental implications.

Given the results above and the current local ecological conditions of Yelang Lake, the high Cd sediment content was mainly attributed to the continuous pollutant inputs into the water from large amounts of untreated urban waste, contaminated soil, industrial wastewater, and domestic sewage, as well as atmospheric deposits. $\mathrm{Zn}$ and $\mathrm{Pb}$ exhibited the second-highest level of pollution, likely due to the existence of large abandoned $\mathrm{Pb}-\mathrm{Zn}$ mines at the upstream of Yelang Lake. Large amounts of $\mathrm{Zn}$ and $\mathrm{Pb}$ in the untreated slag could be released into the water bodies as a result of water flushing.

3.5. Correlation Analysis between Heavy Metals. The similarity of geochemical conditions and the coexistence of heavy metals in the pollution sources led to a certain degree of correlation between the bulk sediment content of different heavy metals [16]. Significant or extremely significant correlations between heavy metals suggest that they are generally derived from the same source(s) or coexist to form combined pollution [17]. Table 6 reflects the correlation factors of the heavy metals in the WLFZ sediment at the Shawan River section of Yelang Lake. There was a significant positive correlation between $\mathrm{Pb}$ and $\mathrm{Cu}, \mathrm{Cd}, \mathrm{Mn}$, and $\mathrm{Zn}$, but no significant correlation between $\mathrm{Pb}$ and $\mathrm{Cr}$. $\mathrm{Cr}$ did not have a significant correlation with any other heavy metal. Cd was positively correlated with $\mathrm{Zn}$ but not with $\mathrm{Mn}$ and $\mathrm{Cu}$. There was an evident positive correlation between $\mathrm{Cu}$ and $\mathrm{Zn}$, and a very remarkable positive correlation between $\mathrm{Cu}$ and Mn. There was an extremely obvious positive correlation between $\mathrm{Zn}$ and $\mathrm{Mn}$. Overall, except for $\mathrm{Cr}$, which was 
TABle 6: Pearson correlation coefficients between the sediment content of heavy metals.

\begin{tabular}{ccccccc}
\hline & $\mathrm{Pb}$ & $\mathrm{Cr}$ & $\mathrm{Cd}$ & $\mathrm{Cu}$ & $\mathrm{Zn}$ & $\mathrm{Mn}$ \\
\hline $\mathrm{Pb}$ & 1 & & & & & \\
$\mathrm{Cr}$ & 0.970 & 1 & & & & \\
$\mathrm{Cd}$ & $0.434^{* *}$ & 0.073 & 1 & & & \\
$\mathrm{Cu}$ & $0.735^{* *}$ & 0.146 & 0.113 & 1 & & \\
$\mathrm{Zn}$ & $0.728^{* *}$ & -0.298 & $0.345^{*}$ & $0.406^{*}$ & 1 & \\
$\mathrm{Mn}$ & $0.592^{* *}$ & 0.164 & 0.141 & $0.753^{* *}$ & $0.556^{* *}$ & 1 \\
\hline
\end{tabular}

${ }^{*} P<0.05$ and ${ }^{* *} P<0.01$.

relatively independent of other heavy metals; most of the heavy metals had significant or extremely significant positive correlations with each other. In other words, most of the heavy metals had a close interrelationship, which increased the pollution risk of heavy metals in the region, namely through the probability of several heavy metals combined pollution simultaneously. However, the correlation results among heavy metals in this study are generally inconsistent with the reports on other WLFZs [18], which may be attributed to the fact that correlations among heavy metals depend not only on geochemical characteristics but also on whether each heavy metal in the region is derived from the same source(s).

\section{Conclusion}

The surface sediment grain size of the WLFZ of the Shawan River section of Yelang Lake was primarily $>0.063 \mathrm{~mm}$ and was dominated by large grains. The grain-size dependence for the content of heavy metal in WLFZ sediment at the Shawan River section of Yelang Lake was not significant. The distributional properties of heavy metals in sediments were studied, and the influence of sediment particle size composition on the distribution of heavy metals was analyzed in this study. However, the behavior of heavy metals is influenced by a variety of factors. It is necessary to explore the effects of the structural composition and specific surface area of sediment grain-size fractions on the distributional properties of heavy metals in sediment.

The site-averaged mean sediment content of each of the six studied heavy metals in the WLFZ was obviously higher than their respective geochemical background content. In particular, Cd exhibited the most severe pollution and made a dominant contribution to the RI, thereby having important environmental implications. There were significant differences among different WLFZ sampling sites in the sediment content of $\mathrm{Pb}, \mathrm{Zn}$, and $\mathrm{Cr}(P<0.05)$ but no notable differences in $\mathrm{Mn}, \mathrm{Cd}$, and $\mathrm{Cu}$ sediment content $(P>0.05)$. The surface sediments of the WLFZ of the research area were strongly contaminated by heavy metals.

Except for Cr, which was relatively independent of other heavy metals, most of the heavy metals had significant or extremely significant positive correlations with each other. In other words, most of the heavy metals had a close interrelationship, which increased the pollution risk of heavy metals in the region, namely the probability of several heavy metals combined pollution simultaneously.

\section{Data Availability}

The data used to support the findings of this study are available from the corresponding author upon request.

\section{Conflicts of Interest}

The authors declare that they have no conflicts of interest.

\section{Acknowledgments}

This study was supported by the Creative Research Groups support program of the Guizhou education department (no. KY [2017]049), the Science and Technology Plan Project of Science and Technology Bureau in Anshun (no. [2018]5), and the Guizhou Province Key Laboratory of Ecological Protection and Restoration of Typical Plateau Wetlands (no. [2020]2002).

\section{References}

[1] Y. Bao, P. Gao, and X. He, "The water-level fluctuation zone of Three Gorges Reservoir - a unique geomorphological unit," Earth-Science Reviews, vol. 150, pp. 14-24, 2015.

[2] C. Micó, L. Recatalá, M. Peris, and J. Sánchez, “Assessing heavy metal sources in agricultural soils of an European Mediterranean area by multivariate analysis," Chemosphere, vol. 65 , no. 5, pp. 863-872, 2006.

[3] H. M. Fernandes, "Heavy metal distribution in sediments and ecological risk assessment: the role of diagenetic processes in reducing metal toxicity in bottom sediments," Environmental Pollution, vol. 97, no. 3, pp. 317-325, 1997.

[4] A. Facchinelli, E. Sacchi, and L. Mallen, "Multivariate statistical and GIS-based approach to identify heavy metal sources in soils," Environmental Pollution, vol. 114, no. 3, pp. 313-324, 2001.

[5] F. Zhou, H. Guo, and L. Liu, "Quantitative identification and source apportionment of anthropogenic heavy metals in marine sediment of Hong Kong," Environmental Geology, vol. 53, no. 2, pp. 295-305, 2007.

[6] C. A. Atkinson, D. F. Jolley, and S. L. Simpson, "Effect of overlying water $\mathrm{pH}$, dissolved oxygen, salinity and sediment disturbances on metal release and sequestration from metal contaminated marine sediments," Chemosphere, vol. 69, no. 9, pp. 1428-1437, 2007.

[7] C. N. Duong, D. Schlenk, N. I. Chang, and S. D. Kim, "The effect of particle size on the bioavailability of estrogenic chemicals from sediments," Chemosphere, vol. 76, no. 3, pp. 395-401, 2009.

[8] Y. T. Zong and G. Lu, "Distribution, bioavailability, and leachability of heavy metals in soil particle size fractions of urban soils ( northeastern China)," Environmental Science And Pollution Research, vol. 23, no. 14, pp. 14600-14607, 2016.

[9] X.-J. Zhang, Y.-T. Zhang, Q.-Y. Zhang, and H.-L. Chen, "Heavy metal distribution in sediment and water of a Lake and its input rivers in an abandoned lead and zinc mine," Journal of Chemical Engineering of Japan, vol. 52, no. 4, pp. 362-368, 2019.

[10] W. Zhang, L. Yu, M. Lu, S. M. Hutchinson, and H. Feng, "Magnetic approach to normalizing heavy metal concentrations for particle size effects in intertidal sediments in the Yangtze estuary, China," Environmental Pollution, vol. 147, no. 1, pp. 238-244, 2007. 
[11] K. S. Murray, D. Cauvet, M. Lybeer, and J. C. Thomas, "Particle size and chemical control of heavy metals in bed sediment from the Rouge river, southeast Michigan," Environmental Science \& Technology, vol. 33, no. 7, pp. 987-992, 1999.

[12] J. Qian, X.-Q. Shan, Z.-J. Wang, and Q. Tu, "Distribution and plant availability of heavy metals in different particle-size fractions of soil," The Science of the Total Environment, vol. 187, no. 2, pp. 131-141, 1996.

[13] G. Z. Du and M. R. Gao, "Fractal characteristics of soil particles in typical water level fluctuating Zone in the Three Gorges reservoir area," Journal of Nanjing Forestry University (Natural Sciences Edition), vol. 1, pp. 47-50, 2011.

[14] E. Z. Ochieng, J. O. Lalah, and S. O. Wandiga, "Heavy metals in water and surface sediments in Winam Gulf of Lake Victoria, Kenya," Bulletin of Environmental Contamination and Toxicology, vol. 77, no. 3, pp. 459-468, 2006.

[15] X. L. Zhong, S. L. Zhou, M. L. Huang, and Q. G. Zhang, "Chemical form distribution characteristic of soil heavy metals and its influencing factors," Ecology and Environmental Sciences, vol. 18, no. 4, pp. 1266-1273, 2009.

[16] S. J. Xu, S. Q. Wei, and D. T. Xie, "Characteristics of heavy metals distribution in cultivated soil in three gorge reservoir area (TGRA)," Journal of Soil and Water Conservation, vol. 17, no. 4, pp. 64-66, 2003.

[17] S. W. Chai, Y. M. Wen, Y. N. Zhang et al., "The heavy metal content character of agriculture soil in Guangzhou suburbs," China Environmental Science, vol. 23, no. 6, pp. 592-596, 2003.

[18] L. Q. Liu, S. Q. Wei, and T. Jiang, "Distribution of soil heavy metals from water-level-fluctuating zone in three-Gorge reservoir Area and their evaluation of potential ecological risk," China Environmental Science, vol. 31, no. 7, 2011. 